\title{
Nuclear structure and reaction studies near doubly magic ${ }^{270} \mathrm{Hs}$
}

\author{
By A. Türler ${ }^{1,2, *}$ \\ ${ }^{1}$ Departement für Chemie und Biochemie, Universität Bern, 3012 Bern, Switzerland \\ 2 Labor für Radio- und Umweltchemie, Paul Scherrer Institut, 5232 Villigen, Switzerland
}

(Received February 2, 2011; accepted in final form May 20, 2011)

\section{Superheavy elements / Hassium / Nuclear structure / Reaction studies}

Summary. Fast on-line gas chemical separations of Hs (hassium, element 108) in the form of $\mathrm{HsO}_{4}$ were applied to investigate the reactions ${ }^{26} \mathrm{Mg}+{ }^{248} \mathrm{Cm}$ and ${ }^{36} \mathrm{~S}+{ }^{238} \mathrm{U}$. In an experiment at the gas-filled separator DGFRS the reaction ${ }^{48} \mathrm{Ca}+{ }^{226} \mathrm{Ra}$ was studied. In all cases the product of complete nuclear fusion is ${ }^{274} \mathrm{Hs}^{*}$. For the first time, the new nuclide ${ }^{270} \mathrm{Hs}$ was produced in the $4 n$ evaporation channel and its decay properties investigated. The nuclide ${ }^{270} \mathrm{Hs}$ was predicted by microscopic-macroscopic calculations to be a deformed doubly magic nucleus and its decay properties are therefore of special interest to theory. Also, much more detailed information was gained on the decay of ${ }^{269} \mathrm{Hs}$ and its daughters, which led to a new assignment of decay properties of the daughter nuclides ${ }^{265} \mathrm{Sg}$ and ${ }^{261} \mathrm{Rf}$. There is evidence for isomeric states in ${ }^{265} \mathrm{Sg}$ and ${ }^{261} \mathrm{Rf}$, while ${ }^{266} \mathrm{Sg}$ is not an alpha-particle emitter as believed previously, but decays by spontaneous fission (SF) with a rather short half-life. Also, interesting features of the used reaction ${ }^{26} \mathrm{Mg}+{ }^{248} \mathrm{Cm}$ led to the discovery of the nucleus ${ }^{271} \mathrm{Hs}$ in the same experiments. An investigation of the influence of the $Q$-value on the fusion reaction in relation to the location of the fusion barrier showed, that the high binding energy of ${ }^{48} \mathrm{Ca}$ largely compensates for the lower fusion probability compared to more asymmetric reactions, while ${ }^{36} \mathrm{~S}$ is not as promising as a projectile.

\section{Introduction}

Discovery of element 108 (hassium, Hs) was reported in 1984 by Münzenberg et al. [1] using the complete heavy ion fusion reaction ${ }^{208} \mathrm{~Pb}\left({ }^{58} \mathrm{Fe}, 1 n\right){ }^{265} \mathrm{Hs}$. The discovery was accomplished using the Separator for Heavy Ion reaction Products (SHIP). Today, the isotopes ${ }^{263-271} \mathrm{Hs}$ have positively been identified [2-16]. Furthermore, one $\alpha$-decay of ${ }^{273} \mathrm{Hs}$ with a life-time of $0.346 \mathrm{~s}$ [17], $3 \alpha$-decays of ${ }^{275} \mathrm{Hs}$ with a half-life of $0.19 \mathrm{~s}$ [18], and one SF decay of ${ }^{277} \mathrm{Hs}$ as decay product of ${ }^{289} 114$ with a lifetime of $4.5 \mathrm{~ms}$ have been reported recently [19]. Hassium is therefore the heaviest transactinide element for which a relatively large number of isotopes (12) are known that cover 15 different neutron numbers (see Fig. 1). First experimental evidence that proton number 108 is a magic number was observed in the decay chain of the nuclide ${ }^{277} \mathrm{Cn}$. There, the $Q_{\alpha}$-value dropped

\footnotetext{
*E-mail: andreas.tuerler@psi.ch.
}

from ${ }^{273} \mathrm{Ds}$ to ${ }^{269} \mathrm{Hs}$ by about $2 \mathrm{MeV}$, while the corresponding half-lives increased by 5 orders of magnitude [11-13]. Relatively large differences of $Q_{\alpha}$-values from Ds and Hs of about 1.4 to almost $2 \mathrm{MeV}$ can be observed for isotones at $N=159,160,161$, and 163 . The stabilization of neutron shells is reflected by local minima of $Q_{\alpha}$ near and at magic neutron numbers. While the currently known, most neutron-deficient ${ }^{263} \mathrm{Hs}$ is still 3 neutron numbers away from the neutron-shell $N=152$, the nucleus ${ }^{270} \mathrm{Hs}$ was predicted to be a "doubly magic" deformed nucleus, with $N=162$ being a magic neutron number [20-22]. Due to the special place hassium occupies in the chart of nuclides, the experimental investigation of the synthesis of hassium isotopes is very interesting, since the calculated shell correction energies at and near ${ }^{270} \mathrm{Hs}$ are very similar to the ones of yet undiscovered nuclei near $Z=114$ and $N=184$. The nucleus ${ }^{277} \mathrm{Hs}$, which is the most neutron-rich hassium isotope observed so far, lies only one neutron number away from the mid-shell nucleus ${ }^{278} \mathrm{Hs}$ with $N=170$. Here, very short SF half-lives were predicted [23].

Different types of nuclear reactions have been used to synthesize hassium isotopes. Neutron-deficient hassium were produced in so-called "cold" fusion reactions using the reactions ${ }^{208} \mathrm{~Pb}\left({ }^{56} \mathrm{Fe}, 1 n\right){ }^{263} \mathrm{Hs} \quad[2,3],{ }^{207} \mathrm{~Pb}\left({ }^{58} \mathrm{Fe}, 1 n\right){ }^{264} \mathrm{Hs}$, and ${ }^{208} \mathrm{~Pb}\left({ }^{58} \mathrm{Fe}, 1 n\right){ }^{265} \mathrm{Hs}$ [5]. The more neutron-rich ${ }^{266} \mathrm{Hs}$, ${ }^{267} \mathrm{Hs}$, and ${ }^{269} \mathrm{Hs}$ were observed for the first time as daughters of ${ }^{270} \mathrm{Ds},{ }^{271} \mathrm{Ds}$, and ${ }^{277} \mathrm{Cn}$ produced in the cold fusion reactions ${ }^{207} \mathrm{~Pb}\left({ }^{64} \mathrm{Ni}, 1 n\right)[6],{ }^{208} \mathrm{~Pb}\left({ }^{64} \mathrm{Ni}, 1 n\right)$ [7-9], and ${ }^{208} \mathrm{~Pb}\left({ }^{70} \mathrm{Zn}, 1 n\right)[11-13]$, respectively. The decay properties of ${ }^{269} \mathrm{Hs}$ were confirmed in a chemistry experiment [14] using the "hot" fusion reaction ${ }^{248} \mathrm{Cm}\left({ }^{26} \mathrm{Mg}, 5 n\right)$, allowing the direct production of this nuclide with a significantly higher production rate than in the reaction ${ }^{208} \mathrm{~Pb}\left({ }^{70} \mathrm{Zn}, 1 n\right)$ ${ }^{277} \mathrm{Cn}$. Chemical investigations played an important role and led to the discovery of the new isotopes ${ }^{270} \mathrm{Hs}$ and ${ }^{271} \mathrm{Hs}[15,16]$. The compound nucleus ${ }^{274} \mathrm{Hs}^{*}$ can be synthesized in four different experimentally possible heavy ion fusion reactions with different reaction asymmetry and reaction $Q$-values. These are the reactions ${ }^{26} \mathrm{Mg}+{ }^{248} \mathrm{Cm}$, ${ }^{30} \mathrm{Si}+{ }^{244} \mathrm{Pu},{ }^{36} \mathrm{~S}+{ }^{238} \mathrm{U}$, and ${ }^{48} \mathrm{Ca}+{ }^{226} \mathrm{Ra}$. In the 4-neutron evaporation channel, ${ }^{270} \mathrm{Hs}$ with maximum shell correction energy is produced. The formation of very volatile $\mathrm{HsO}_{4}$ allowed using on-line gas phase chemistry that provided unsurpassed efficiency independently of the used nuclear synthesis reaction, the only limitation being the half-life of the investigated nuclide. Identification of ${ }^{268} \mathrm{Hs}$ using the 


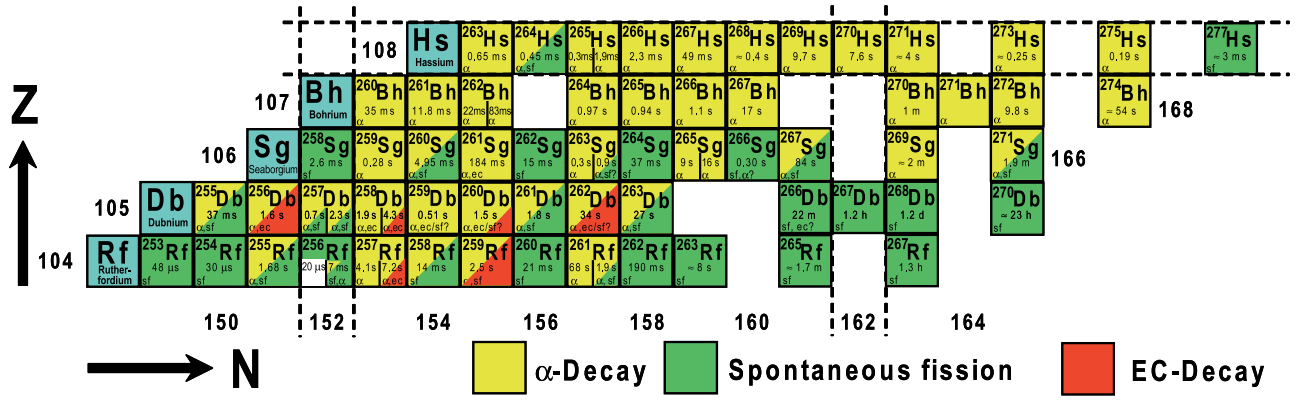

Fig. 1. Cut-out of the chart of nuclides for atomic numbers $104 \leq$ $Z \leq 108$. Proton and neutron shells are indicated by dashed lines. reaction ${ }^{248} \mathrm{Cm}\left({ }^{25} \mathrm{Mg}, 5 n\right)$ by chemical means was unsuccessful, probably due to the rather short half-life [24]. This nuclide was observed only recently by Nishio et al. [10] at the SHIP using the reaction ${ }^{238} \mathrm{U}\left({ }^{34} \mathrm{~S}, 4 n\right){ }^{268} \mathrm{Hs}$. In addition, a new reaction mechanism for heavy element synthesis can also be explored, namely the symmetric fusion of two nuclei i.e. in the reaction ${ }^{136} \mathrm{Xe}\left({ }^{136} \mathrm{Xe}, 2 n\right){ }^{270} \mathrm{Hs}$ [25].

In the following, the latest results on the synthesis of Hs isotopes will be reviewed. Emphasis will be laid on the synthesis of nuclides near and at $Z=108$ and $N=162$ in different asymmetric heavy ion fusion reactions. Besides the knowledge gained about the synthesis reactions, also new nuclear decay data was obtained for several hassium isotopes and their Sg and Rf daughters [26].

\section{Nuclear structure near $Z=108$ and $N=162$}

\subsection{Nuclear shell effects}

Superheavy elements owe their existence exclusively to nuclear shell effects, which stabilize them against SF. In Fig. 2 calculated shell correction energies of nuclei from the last known stable, doubly magic nucleus ${ }^{208} \mathrm{~Pb}$ with spherical shape to the predicted island of stability at $Z=114$ and $N=184$, deduced from microscopic-macroscopic calculations by Sobiczewski et al. [27] are shown. Two regions of increased stability with maximum shell correction energies of more than $7 \mathrm{MeV}$ are visible. The center of the smaller region is located at $Z=108$ and $N=162$ and the larger one with slightly higher shell correction energies at $Z=114$ and

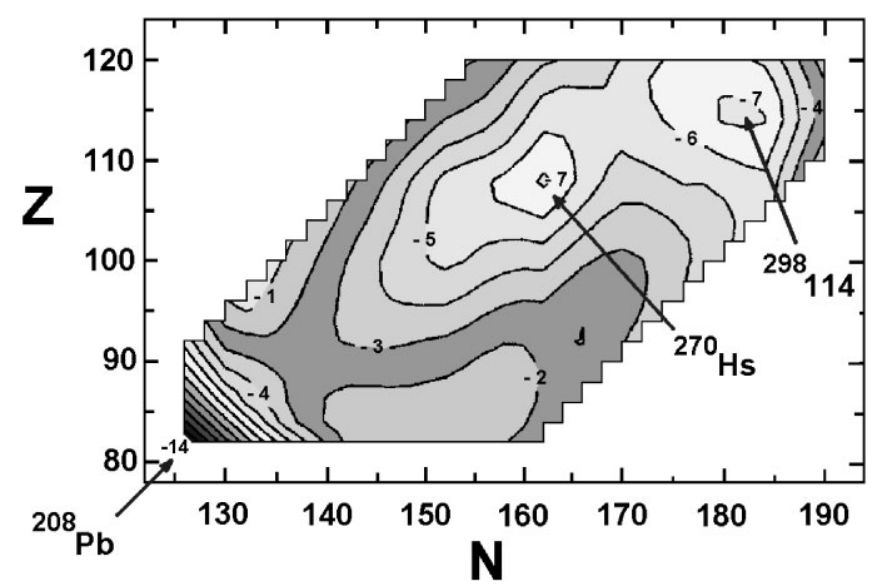

Fig. 2. Contour map of the ground-state shell correction energy. Figure adopted by Sobiczewski et al. [27]. The location of the doubly magic nuclei ${ }^{208} \mathrm{~Pb},{ }^{270} \mathrm{Hs}$ and ${ }^{298} 114$ are indicated.
$N=184$. This new area of increased stability at and near $N=162$ and $Z=108$ corresponds to gaps in the singleparticle spectra which appear only at deformed shapes. By using a larger deformation space and a dynamic treatment of the fission barriers, Patyk et al. [20,21] analyzed the singleparticle spectra of heavy nuclei and predicted ${ }^{270} \mathrm{Hs}$ to be a relatively strongly bound "doubly-magic" deformed nucleus.

\subsection{Predicted $\alpha$-decay half-lives, spontaneous fission barrier heights and fission half-lives}

${ }^{270} \mathrm{Hs}$ is expected to decay predominantly by $\alpha$-particle emission with $Q_{\alpha}=9.44 \mathrm{MeV}$ [21]. In a later publication, this value was reduced to $Q_{\alpha}=9.13 \mathrm{MeV}$ [27], resulting in a partial $\alpha$-decay half-life of about $6 \mathrm{~s}$, whereas the partial SF-decay half-life was predicted to be $1.8 \mathrm{~h}$ [23]. Decay energies of $Q_{\alpha}=8.7-9.9 \mathrm{MeV}$ have been derived from mass tables $[28,29], Q_{\alpha}=8.9 \mathrm{MeV}$ was calculated by Ren et al. [30] in the framework of the relativistic mean-field theory. A recent analysis, which investigated SF-barriers of even-even superheavy nuclides within the framework of the macroscopic-microscopic approach, came to the conclusion that the static fission barriers for nuclei with $98<Z<126$ were all lower than $7 \mathrm{MeV}$ [31]. Highest static fission barriers were calculated for ${ }^{270} \mathrm{Hs}(6.42 \mathrm{MeV}),{ }^{292} 114(6.34 \mathrm{MeV})$ and for nuclei near $Z=100$ and $N=150$.

\subsection{Rotational states}

Since nuclei near $Z=108$ and $N=162$ are predicted to have deformed shape, which, e.g., could be proved experimentally by measuring, the lowest energy of the $2+$ state $\left(E_{2+}\right)$ of even-even nuclei. This could be accomplished by observing $\alpha$-decay of even-even nuclei to the $0+$ and the $2+$ rotational state of the daughter nucleus by high-resolution $\alpha$-decay- or electron spectroscopy. The $E_{2+}$ energies and the $p_{2+} / p_{0+}$ branching ratios have been calculated by Sobiczewski et al. [27]. For the nucleus ${ }^{270} \mathrm{Hs}$ they predicted a deformation energy of $7.8 \mathrm{MeV}$. The daughter nucleus ${ }^{266} \mathrm{Sg}$ has an $E_{2+}$ energy of $45.0 \mathrm{keV}$ and the branching ratio for decay of ${ }^{270} \mathrm{Hs}$ to the ${ }^{266} \mathrm{Sg} 2+$ state $\left(p_{2+} / p_{0+}\right)$ was calculated as $7.7 \%$.

\section{Early experimental evidence for a shell closure near $Z=108$ and $N=162$}

Discovery of enhanced nuclear stability near the deformed shells $N=162$ and $Z=108$ was claimed in 1994 by 


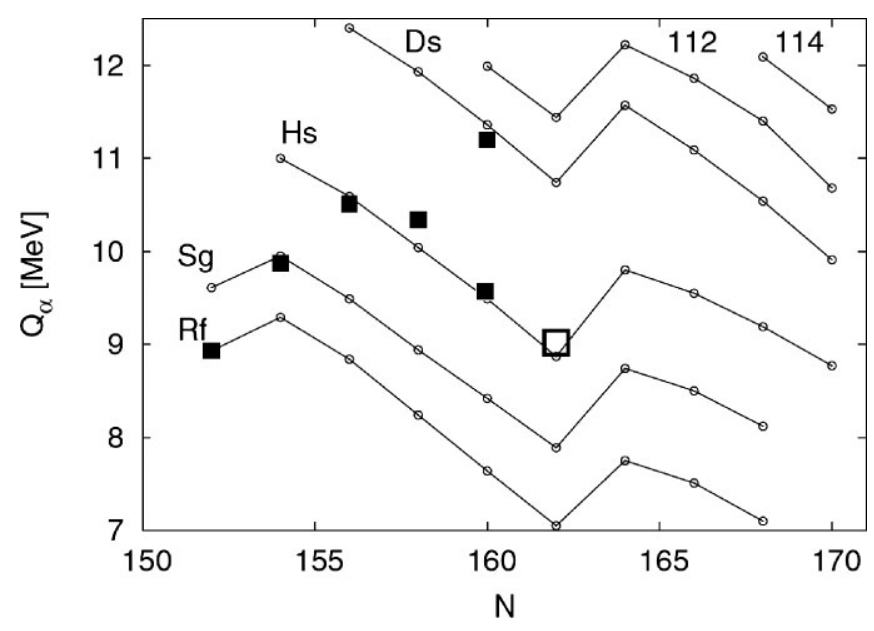

Fig. 3. Comparison of $Q_{\alpha}$ values from theoretical calculations [41] and experimental data.

Lazarev et al. [32], by reporting $\alpha$-decay as the main decay mode and relatively long half-lives for the newly synthesized nuclides ${ }^{265} \mathrm{Sg}$ and ${ }^{266} \mathrm{Sg}$. However, as will be discussed later in this paper, the reported discovery of ${ }^{266} \mathrm{Sg}$ was not correct. The complete fusion reaction ${ }^{248} \mathrm{Cm}\left({ }^{22} \mathrm{Ne}, x n\right){ }^{270-x} \mathrm{Sg}$ was studied at the Dubna Gas-Filled Recoil Separator (DGFRS) to search for new, relatively neutron-rich isotopes of seaborgium. Indeed, six decay chains where registration of an $\alpha$ particle was followed by the observation of a genetically correlated spontaneous fission (SF), i.e., of the type $\alpha-\mathrm{SF}$ and five decay chains of the type $\alpha-\alpha(-\alpha)$ were observed and assigned to ${ }^{265} \mathrm{Sg}(\alpha-\alpha-\alpha)$ and ${ }^{266} \mathrm{Sg}(\alpha-\mathrm{SF})$, produced in the $5 n$ and $4 n$ evaporation channel, respectively. Assignment to a specific exit channel was mainly based on the decay properties of the daughters, ${ }^{261} \mathrm{Rf}$ and ${ }^{262} \mathrm{Rf}$, as known at that time: ${ }^{261} \mathrm{Rf}$ was reported to decay exclusively by emission of $8.28 \mathrm{MeV} \alpha$ particles with a half-life of $\approx 65 \mathrm{~s}$ [33], whereas ${ }^{262} \mathrm{Rf}$ had been reported to decay by SF with $47 \pm 5 \mathrm{~ms}$ half-life [34], or, later by SF with $2.1 \mathrm{~s}$ halflife [35]. Thus, it appeared straightforward to assign $\alpha-\alpha(-\alpha)$ chains to the mother of ${ }^{261} \mathrm{Rf}$, i.e., ${ }^{265} \mathrm{Sg}$, and $\alpha$-SF chains to the mother of ${ }^{262} \mathrm{Rf}$, i.e., ${ }^{266} \mathrm{Sg}$. The reaction ${ }^{22} \mathrm{Ne}+{ }^{248} \mathrm{Cm}$ was employed in various experiments. Due to the relatively long reported half-lives of ${ }^{265,266} \mathrm{Sg}$, this reaction was used notably in most studies aiming at investigating the chemical properties of seaborgium [36-40]. As in the original work [32], $\alpha-\alpha(-\alpha)$ chains were assigned to ${ }^{265} \mathrm{Sg}$ and $\alpha$-SF chains to ${ }^{266} \mathrm{Sg}$. Further experiments on the daughters, ${ }^{261} \mathrm{Rf}$ and ${ }^{262} \mathrm{Rf}$ were performed as well, basically supporting the early work.

A different perspective concerning the interpretation of the data of Lazarev et al. [32] provided the identification of the nucleus ${ }^{277} \mathrm{Cn}$ and its long chain of successive $\alpha$-decays that proceed also through ${ }^{265} \mathrm{Sg}$ and ${ }^{261} \mathrm{Rf}$ [11]. Experimental evidence that proton number 108 is a magic number was observed in the decay chain of the nuclide ${ }^{277} \mathrm{Cn}$. There, the $Q_{\alpha}$-value dropped from ${ }^{273} \mathrm{Ds}$ to ${ }^{269} \mathrm{Hs}$ by about $2 \mathrm{MeV}$, while the corresponding half-lives increased by 5 orders of magnitude [11-13]. As shown in Fig. 3, relatively large differences of $Q_{\alpha}$-values from Ds and Hs of about 1.4 to almost $2 \mathrm{MeV}$ can be observed for isotones at $N=159,160,161$, and 163. The stabilization of neutron shells is reflected by local minima of $Q_{\alpha}$ near and at magic neutron numbers.

\section{Reactions leading to the compound nucleus ${ }^{274} \mathbf{H s}^{*}$}

In the case of the doubly magic nucleus ${ }^{270} \mathrm{Hs}$, different reactions, leading to the same compound nucleus $(\mathrm{CN}){ }^{274} \mathrm{Hs}$ can be studied with the aim to investigate the influence of mass asymmetry and the $(B-Q)$-value on the $\mathrm{CN}$ nucleus formation in the entrance channel. These are ${ }^{26} \mathrm{Mg}+$ ${ }^{248} \mathrm{Cm},{ }^{30} \mathrm{Si}+{ }^{244} \mathrm{Pu},{ }^{36} \mathrm{~S}+{ }^{238} \mathrm{U}$, and ${ }^{48} \mathrm{Ca}+{ }^{226} \mathrm{Ra}$. Bass barrier, $Q$-value, $(B-Q)$-values and $Z_{1} \times Z_{2}$ (proportional to the reaction asymmetry) are displayed in Table 1 . As can be seen, these reactions differ in their asymmetry, from the most asymmetric reaction ${ }^{26} \mathrm{Mg}+{ }^{248} \mathrm{Cm}$ to the most symmetric reaction ${ }^{48} \mathrm{Ca}+{ }^{226} \mathrm{Ra}$, as well as in their excitation energy at the center-of-mass energy equal to the Bass fusion barrier $(B-Q)$. Here, the reaction ${ }^{48} \mathrm{Ca}+{ }^{226} \mathrm{Ra}$ has the lowest and hence the most favorable value. The reaction ${ }^{30} \mathrm{Si}+{ }^{244} \mathrm{Pu}$ has the highest and thus the most unfavorable value. The interesting question is which of both parameters is dominant and hence, which of the reactions is the best one compared with the others.

Recently, the formation of the deformed doubly-magic nucleus ${ }^{270} \mathrm{Hs}$ in the $4 n$ evaporation channel in the complete fusion reactions ${ }^{248} \mathrm{Cm}\left({ }^{26} \mathrm{Mg}, 4 n\right),{ }^{244} \mathrm{Pu}\left({ }^{30} \mathrm{Si}, 4 n\right)$, ${ }^{238} \mathrm{U}\left({ }^{36} \mathrm{~S}, 4 n\right)$, and ${ }^{226} \mathrm{Ra}\left({ }^{48} \mathrm{Ca}, 4 n\right)$ has been studied theoretically in more detail using a two-parameter Smoluchowski equation by Liu et al. [42]. Due to a lower reaction $Q$-value, the reactions ${ }^{238} \mathrm{U}\left({ }^{36} \mathrm{~S}, 4 n\right){ }^{270} \mathrm{Hs}\left(\sigma_{\text {theo }}=24 \mathrm{pb}\right)$ and ${ }^{226} \mathrm{Ra}\left({ }^{48} \mathrm{Ca}, 4 n\right){ }^{270} \mathrm{Hs} \quad\left(\sigma_{\text {theo }}=30 \mathrm{pb}\right)$ were predicted to have higher cross sections compared to the reactions ${ }^{248} \mathrm{Cm}\left({ }^{26} \mathrm{Mg}, 4 n\right){ }^{270} \mathrm{Hs} \quad\left(\sigma_{\text {theo }}=12 \mathrm{pb}\right)$ and ${ }^{244} \mathrm{Pu}\left({ }^{30} \mathrm{Si}, 4 n\right)$ ${ }^{270} \mathrm{Hs}\left(\sigma_{\text {theo }}=8 \mathrm{pb}\right)$.

As an alternative, calculations with the model code HIVAP using the standard parameter set for actinide based fusion reactions by Reisdorf and Schädel [43] were performed using a version by Heßberger (7.6.1994) from GSI Darmstadt. The HIVAP code takes into account a dynamically fluctuating barrier for the fusion probability to

Table 1. Bass barrier, $Q$-value, $(B-Q)$-values and $Z_{1} \times Z_{2}$ for various reactions leading to the $\mathrm{CN}^{274} \mathrm{Hs}$.

\begin{tabular}{|c|c|c|c|c|c|c|c|c|c|c|}
\hline Reaction & $\begin{array}{c}B \\
(\mathrm{MeV})\end{array}$ & $\begin{array}{c}Q \\
(\mathrm{MeV})\end{array}$ & $\begin{array}{c}(B-Q) \\
(\mathrm{MeV})\end{array}$ & $Z_{1} \times Z_{2}$ & $\begin{array}{c}\sigma_{\max } \\
E^{*}\end{array}$ & $\begin{array}{c}{ }^{270} \mathrm{Hs}[42] \\
(\mathrm{pb})\end{array}$ & $\underset{E^{*}}{\sigma_{\max }}$ & $\begin{array}{c}{ }^{270} \mathrm{Hs}[43] \\
(\mathrm{pb})\end{array}$ & $\underset{E^{*}}{\sigma_{\max }}$ & $\begin{array}{c}{ }^{270} \mathrm{Hs}[44] \\
(\mathrm{pb})\end{array}$ \\
\hline${ }^{26} \mathrm{Mg}+{ }^{248} \mathrm{Cm}$ & 126.9 & -82.2 & 44.7 & 1152 & 43 & 12 & 40 & 2 & & \\
\hline${ }^{30} \mathrm{Si}+{ }^{244} \mathrm{Pu}$ & 144.0 & -98.0 & 46.0 & 1316 & 44 & 8 & 37 & 2 & & \\
\hline${ }^{36} \mathrm{~S}+{ }^{238} \mathrm{U}$ & 159.1 & -116.7 & 42.4 & 1472 & 40 & 24 & 37 & 3 & & \\
\hline${ }^{48} \mathrm{Ca}+{ }^{226} \mathrm{Ra}$ & 187.0 & -153.9 & 33.1 & 1760 & 37 & 30 & 36 & 10 & 40 & 30 \\
\hline
\end{tabular}


account among other effects for the orientational barrier fluctuation of the deformed actinide target nuclei. Results of the calculations of the complete nuclear fusion reactions $\left.{ }^{248} \mathrm{Cm}\left({ }^{26} \mathrm{Mg}, x n\right)\right)^{274-x} \mathrm{Hs},{ }^{244} \mathrm{Pu}\left({ }^{30} \mathrm{Si}, x n\right){ }^{274-x} \mathrm{Hs}$, ${ }^{238} \mathrm{U}\left({ }^{36} \mathrm{~S}, x n\right){ }^{274-x} \mathrm{Hs}$, and ${ }^{226} \mathrm{Ra}\left({ }^{48} \mathrm{Ca}, x n\right){ }^{274-x} \mathrm{Hs}$ have been performed and communicated by Düllmann from GSI Darmstadt/University Mainz. For the reactions ${ }^{26} \mathrm{Mg}+$ ${ }^{248} \mathrm{Cm}$ and ${ }^{30} \mathrm{Si}+{ }^{244} \mathrm{Pu}$ the $5 n$ de-excitation channel is predicted to be the dominant one with a predicted maximum cross section of about $4 \mathrm{pb}$ and $3 \mathrm{pb}$, respectively, while the $4 n$ channel reaches a maximum of about $2 \mathrm{pb}$ for both reactions. For the ${ }^{36} \mathrm{~S}+{ }^{238} \mathrm{U}$ reaction, HIVAP predicts the $3 n$ channel to be the dominant channel with a maximum cross section of about $10 \mathrm{pb}$ at an excitation energy of about $30 \mathrm{MeV}$. The $4 n$ and $5 n$ channel are predicted to have maximum cross sections of about $3 \mathrm{pb}$ at $37 \mathrm{MeV}$ and $48 \mathrm{MeV}$, respectively. The $6 n$ channel should provide a maximum cross section of about $0.3 \mathrm{pb}$ at $56 \mathrm{MeV}$. A similar picture is predicted for the ${ }^{48} \mathrm{Ca}+{ }^{226} \mathrm{Ra}$ reaction. Here, the $3 n$ channel is predicted with a maxium cross section of over $100 \mathrm{pb}$ at $29 \mathrm{MeV}$ excitation energy and $10 \mathrm{pb}$ for the $4 n$ channel at $36 \mathrm{MeV}$. It is important to note, that predictions from HIVAP for the $4 n$ channel are about one order of magnitude lower than predictions made by Liu et al. [42].

A maximum cross section for the ${ }^{226} \mathrm{Ra}\left({ }^{48} \mathrm{Ca}, 4 n\right){ }^{270} \mathrm{Hs}$ reaction of about $30 \mathrm{pb}$ was also predicted in other calculations, using a different method [44], which has been shown to reproduce experimental cross sections for various ${ }^{48} \mathrm{Ca}$-based fusion reactions with actinide targets. The calculated excitation functions for the $2 n-5 n$ evaporation channel show, that the $4 n$ channel is the dominant one for this reaction.

\section{Experimental}

The rapidly decreasing production cross-sections, that are of the order of picobarns $\left(10^{-36} \mathrm{~cm}^{2}\right)$ (which translates into the production of single atoms per day or even week of beam time) and the diminishing half-lives to the level of few seconds make manual chemical investigations of elements beyond atomic number 105 (Db, dubnium) virtually impossible. The numerous difficulties involved in the production and the rapid chemical isolation of a few single atoms of a transactinide element from a plethora of other reaction products and the subsequent detection of the nuclear decay, require the development of unique production and separation methods.

\subsection{Production of hassium isotopes}

For the reactions discussed in Sect. 4, exotic, very valuable $\left({ }^{248} \mathrm{Cm},{ }^{244} \mathrm{Pu}\right)$ and/or highly radioactive $\left({ }^{226} \mathrm{Ra}\right)$ target materials have to be handled and safely irradiated with high intensity heavy ion beams. But also all of the isotopes required to produce the beams are rare or very rare (i.e. ${ }^{36} \mathrm{~S}$, $0.01 \%$ nat. isotopic abundance) and have to be purchased in highly enriched form. The results discussed in this contribution were obtained mainly at the UNILAC accelerator of Helmholtzzentrum für Schwerionenforschung (GSI) in Darmstadt using a highly efficient gas-phase chemical separation and detection method.

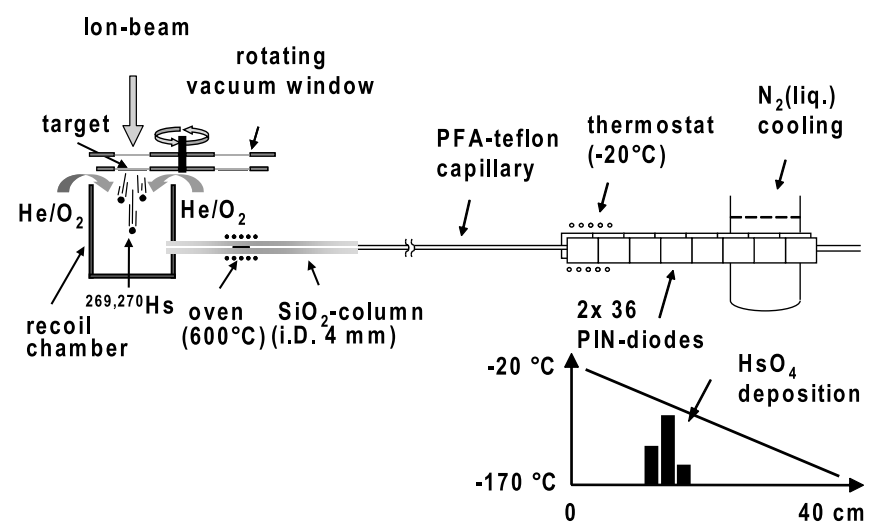

Fig. 4. The projectile beam from the accelerator passed through the rotating vacuum window and the target assembly. In the fusion reaction, ${ }^{269-271} \mathrm{Hs}$ nuclei were formed which recoiled out of the target into a gas volume and were flushed with a $\mathrm{He} / \mathrm{O}_{2}$ mixture to a quartz column containing a quartz wool plug heated to $600{ }^{\circ} \mathrm{C}$ by an oven. There, Hs was converted to $\mathrm{HsO}_{4}$ which is volatile at room temperature and transported with the gas flow through a perfluoroalkoxy (PFA) capillary to the detector array registering the nuclear decay ( $\alpha$ and SF). A thermostat kept the entrance of the array at $20^{\circ} \mathrm{C}$; the exit was cooled to $-170{ }^{\circ} \mathrm{C}$ by means of liquid $\mathrm{N}_{2}$. Depending on the volatility of $\mathrm{HsO}_{4}$, the molecules adsorbed at a characteristic temperature.

The beam of the accelerator is passed through a vacuum window before impinging on the target. The targets consisted usually of a support foil (Be or $\mathrm{Ti}$ ) on which the valuable material was deposited by electrodeposition [45]. Due to the energy loss of the beam in the vacuum window and the target backing a power in excess of $10 \mathrm{~W}$ was generated during the bombardment with typical beam intensities. An effective cooling was necessary to prevent damage to the target and the windows due to overheating. Indeed, the target and window resistance against heat and radiation damages is the limiting factor. In order to distribute the heat over a larger area, the rotating target and vacuum window wheel ARTESIA was used instead of a stationary target. Such a technically challenging irradiation setup was constructed and put into operation by Schädel et al. [46]. The targets consisted of 3 arc shaped segments with thicknesses of up to $1 \mathrm{mg} / \mathrm{cm}^{2}$ (see Fig. 4). Usually, one of the segments contained a small admixture of ${ }^{152} \mathrm{Gd}$ (30\% enrichment) for the simultaneous production of $\alpha$-decaying Os isotopes, a chemical homolog of Hs. The target wheel was rotating at $2000 \mathrm{rpm}$, in synchronization with the beam pulse.

\subsection{Chemical isolation and detection}

For chemical investigations, the element of interest has to be transported rapidly from the location of its production to a chemistry laboratory. In some cases, the element of interest can be converted in-situ to a volatile chemical compound and transported through a capillary to the chemistry laboratory. This transport can be accomplished within few seconds. In order to assess nuclides that are produced with few picobarn cross sections, the overall efficiency has to be as high as possible. Such a case constitutes the chemistry of Hs. If Hs has any resemblance to its lighter homolog Os, then it should also form tetroxides. Due to the perfect tetrahedral symmetry of $\mathrm{OsO}_{4}$, this compound only interacts very weakly with non-reducing surfaces and is therefore very volatile, similar to a noble gas. In experiments with $\mathrm{Hs}$, 
recoiling atoms were converted in-situ with an admixture of $\mathrm{O}_{2}$ gas to the volatile $\mathrm{HsO}_{4}$ [14]. The isolated molecules are detected in a thermochromatography detector. A negative longitudinal temperature gradient is established along an open column through which the carrier gas containing the isolated volatile atoms or molecules is flowing. Compounds are deposited in the chromatography column according to their volatility, forming distinct deposition peaks. If the column consists of silicon detectors, then the nuclear decay of the separated nuclides can be registered. The detector number indicates the temperature at which the volatile compound was deposited. Thus, every detected nuclide reveals chemical information. A schematic of the COMPACT system is shown in Fig. 4. The overall efficiency (including detection of a complete 3 member $\alpha$-particle decay chain) is of the order of $55 \%$.

\section{Results and discussion}

\subsection{Observed nuclear decay properties}

In various experiments on the chemistry and physics of hassium isotopes a number of decay chains attributed to ${ }^{269} \mathrm{Hs}$, ${ }^{270} \mathrm{Hs}$, and ${ }^{271} \mathrm{Hs}$ have been registered. The resulting nuclear decay properties have been summarized in Fig. 5. In the first experiment on the chemical properties of Hs [14] a total of 7 decay chains was observed ( 2 of them were incomplete). In contrast to the original assignment ( 5 decay chains of ${ }^{269} \mathrm{Hs}$ and 2 decay chains of ${ }^{270} \mathrm{Hs}$ ), it later became necessary to assign all the decay chains to ${ }^{269} \mathrm{Hs}$ only [26]. In the experiments to discover the nuclides ${ }^{270} \mathrm{Hs}$ and ${ }^{271} \mathrm{Hs}$ a total of 26 decay chains were observed $[15,16]$. Six of the decay chains were attributed to ${ }^{271} \mathrm{Hs}$ and six to ${ }^{270} \mathrm{Hs}$. Eleven complete decay chains were attributed to ${ }^{269} \mathrm{Hs}$. One decay chain was incomplete and assigned to ${ }^{265} \mathrm{Sg}$ and two further decay chains remained unassigned. All of the above mentioned decay chains were observed using the reaction ${ }^{26} \mathrm{Mg}+{ }^{248} \mathrm{Cm}$.

In the reaction ${ }^{36} \mathrm{~S}+{ }^{238} \mathrm{U}$ only one single decay chain was observed which was attributed to ${ }^{270} \mathrm{Hs}$ [47].

The preliminary analysis of the ${ }^{48} \mathrm{Ca}+{ }^{226} \mathrm{Ra}$ experiment conducted at the Dubna gas-filled separator DGFRS revealed six decay chains that were all attributed to the decay of ${ }^{270} \mathrm{Hs}$ [48].

\subsubsection{Decay properties of ${ }^{269} \mathrm{Hs}$ and its daughters}

In Fig. 6 the $\alpha$-decay spectra of ${ }^{269} \mathrm{Hs}$ and its daughters are shown. The figure contains data from all gas-phase chemistry experiments [14-16] and the data of the 4 decay chains observed for ${ }^{277} \mathrm{Cn}[12,13]$.

As displayed in Fig. 6 it appears that the decay of ${ }^{269} \mathrm{Hs}$ proceeds through two different states in ${ }^{265} \mathrm{Sg}$ and ${ }^{261} \mathrm{Rf}$. Therefore, a reexamination of all data of the decay of ${ }^{265} \mathrm{Sg}$ was performed [26]. Evidence for two isomeric states in ${ }^{265} \mathrm{Sg}$ and ${ }^{261} \mathrm{Rf}$ was clearly observed. Based on this reexamination the different decay branches were evaluated and shown in Fig. 7. These decay patterns and branching ratios have been recently confirmed in independent, yet unpublished results by Haba et al. at RIKEN. In addition to the formation of the long-lived state of ${ }^{261} \mathrm{Rf}\left(T_{1 / 2}=68 \mathrm{~s}\right.$, $E_{\alpha}=8.28 \mathrm{MeV}$ ), direct synthesis of the short-lived isomeric state of ${ }^{261} \mathrm{Rf}$ was recently reported by Haba et al. [49]. This

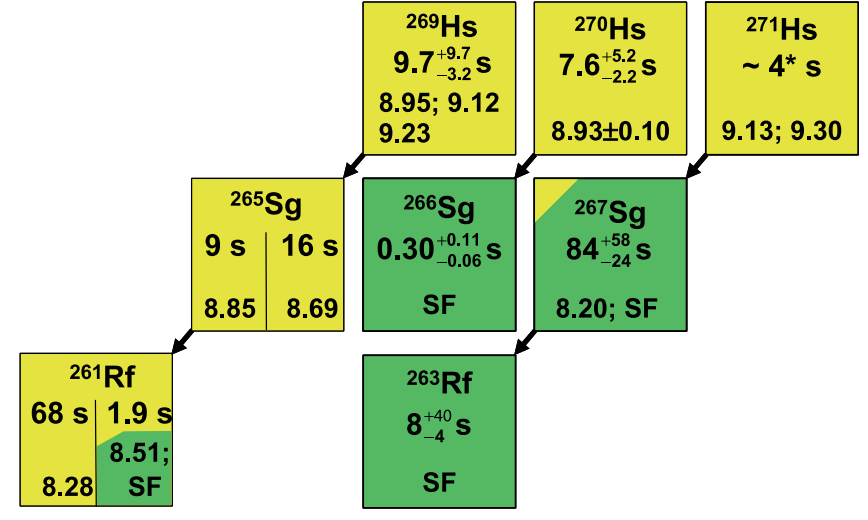

Fig. 5. Decay properties of ${ }^{269,270,271} \mathrm{Hs}$ and their daughters.

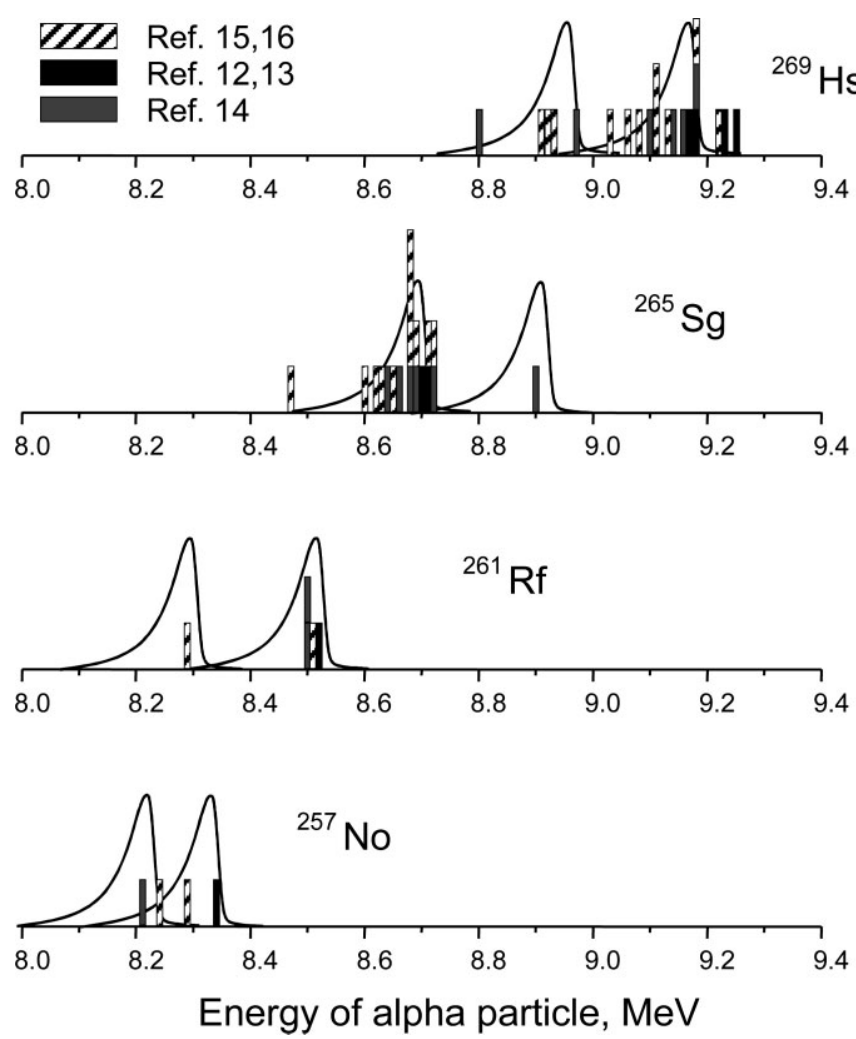

Fig. 6. Alpha-decay spectra of ${ }^{269} \mathrm{Hs}$ and its decay daughters.

state decays by SF (73\%) and alpha-particle emission (27\%) $\left(E_{\alpha}=8.52 \mathrm{MeV}\right)$ with a half-life of $1.9 \mathrm{~s}$. It is interesting to note, that all $\alpha$-decay energies of ${ }^{269} \mathrm{Hs}(9.17-9.25 \mathrm{MeV})$ that were observed as decay daughter of ${ }^{277} \mathrm{Cn}$ and ${ }^{273} \mathrm{Ds}$ are among the highest decay energies observed for this nuclide. One explanation might be that, due to the implantation into a focal plane detector, conversion electron summing occurs. Alternatively, long-lived isomeric states also in ${ }^{269} \mathrm{Hs}$ similar to ${ }^{265} \mathrm{Sg}$ and ${ }^{261} \mathrm{Rf}$ cannot be ruled out. Unfortunately, the chemistry experiments were unable to measure the life times of the observed ${ }^{269} \mathrm{Hs}$, which is an inherent deficit of the gasphase chemistry experiments using thermochromatography detectors.

\subsubsection{Decay properties of ${ }^{270} \mathrm{Hs}$ and its daughter ${ }^{266} \mathrm{Sg}$}

The decay properties of the new doubly magic nucleus ${ }^{270} \mathrm{Hs}$ have now been established and have been confirmed in the 


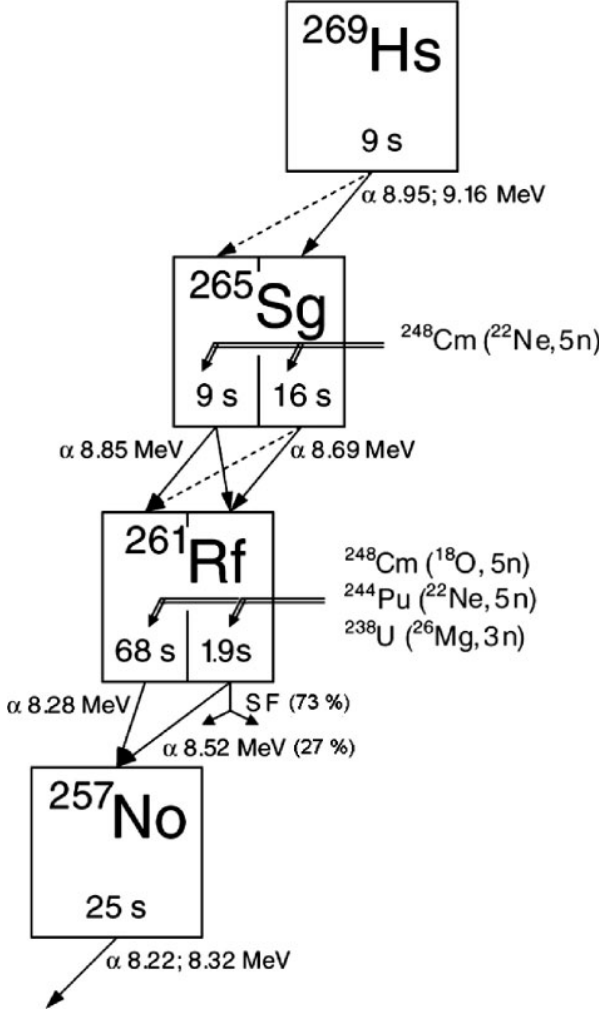

Fig. 7. Branching ratios in the decay chain of ${ }^{269} \mathrm{Hs}$.

yet unpublished data of the ${ }^{48} \mathrm{Ca}+{ }^{226} \mathrm{Ra}$ reaction by Utyonkov et al. at FLNR, Dubna [48]. The preliminary half-life of ${ }^{270} \mathrm{Hs}$ observed in the Dubna experiments agrees relatively well with the predictions of the Viola-Seaborg systematics with $Q_{\alpha}=9.06 \mathrm{MeV}$.

The daughter nucleus ${ }^{266} \mathrm{Sg}$ is consistently decaying by $\mathrm{SF}$ with a half-life of $0.3 \mathrm{~s}$. This is in contrast to earlier measurements by Lazarev et al. [32] where $\alpha$-particle emission was assigned to the decay of ${ }^{266} \mathrm{Sg}$. However, at the time the short lived isomeric state in ${ }^{261} \mathrm{Rf}$ decaying by SF was unknown and mistaken for SF of ${ }^{262} \mathrm{Rf}$. It is therefore conceivable that the decays assigned to ${ }^{266} \mathrm{Sg}$ by Lazarev et al. must actually be assigned to ${ }^{265} \mathrm{Sg}$. Nevertheless, also the validity of the SF half-life of ${ }^{262} \mathrm{Rf}$ has to be questioned and probably be remeasured. A recent experiment at the gasfilled separator TASCA indicated that neither $47 \mathrm{~ms}$ [34] nor $2.1 \mathrm{~s} \mathrm{[35]} \mathrm{were} \mathrm{accurate.} \mathrm{A} \mathrm{new} \mathrm{SF-activity} \mathrm{with} \mathrm{a} \mathrm{half-life}$ of about $0.2 \mathrm{~s}$ was observed [50].

\subsubsection{Decay properties of ${ }^{271} \mathrm{Hs}$ and its daughters}

A rather unusual decay chain was observed at low bombarding energy $\left(E^{*}=40 \mathrm{MeV}\right)$ in the reaction ${ }^{26} \mathrm{Mg}+{ }^{248} \mathrm{Cm}$ [15]. In detector pair 7 a $9.30 \mathrm{MeV} \alpha$-decay was followed $149 \mathrm{~s}$ later by an $8.20 \mathrm{MeV} \alpha$-decay followed $12 \mathrm{~s}$ later by a coincident SF (detection of both fragments). The chemical separation procedure ensured that the decay sequence originated from a hassium isotope or from a daughter nucleus in case the hassium mother was missed and not detected. The sequence is unique in the sense that it did not fit to any previously observed decay chains for ${ }^{269} \mathrm{Hs}$ and ${ }^{270} \mathrm{Hs}$. The relatively low bombarding energy excluded an assignment to, e.g. ${ }^{268} \mathrm{Hs}$ produced in the $6 n$ evaporation channel. The large difference of $1.1 \mathrm{MeV}$ in the subsequent $\alpha$-decay energies indicates that a nuclear shell is being crossed. This is indeed the case for the $\alpha$-decay of ${ }^{271} \mathrm{Hs}$ to ${ }^{267} \mathrm{Sg}$ where the $N=162$ neutron shell is being crossed (see Fig. 3 ). The nuclide ${ }^{271} \mathrm{Hs}$ is produced in the $3 n$ evaporation channel. Indeed, at an even lower excitation energy of $E^{*}=35 \mathrm{MeV}$, four $\alpha$-SF decay sequences with relatively long correlation times were observed, which were assigned to the decay sequence ${ }^{271} \mathrm{Hs} \stackrel{\alpha}{\rightarrow}{ }^{267} \mathrm{Sg}$. Therefore, ${ }^{267} \mathrm{Sg}$ decays predominately by SF with a half-life of $84 \mathrm{~s}$. The nuclide ${ }^{263} \mathrm{Rf}$ was reported to decay by SF with a half-life of about $20 \mathrm{~m}$ by Kratz et al. [51]. The measured life-time of $12 \mathrm{~s}$ appears rather short compared to the above mentioned half-life by Kratz et al., clearly further experiments are needed here. In this context it would be quite interesting to investigate the reaction ${ }^{244} \mathrm{Pu}\left({ }^{26} \mathrm{Mg}, 3 n\right){ }^{267} \mathrm{Sg}$ which quite possibly would provide a higher production cross section and thus production rate for ${ }^{267} \mathrm{Sg}$.

\subsection{Excitation functions}

\subsubsection{Excitation functions of the reaction ${ }^{26} \mathrm{Mg}+{ }^{248} \mathrm{Cm}$}

The reaction that has been studied most intensively is the reaction ${ }^{26} \mathrm{Mg}+{ }^{248} \mathrm{Cm}$ where measurements were performed at five different excitation energies, covering the $3 n, 4 n$, and $5 n$ neutron evaporation channel. The deduced excitation functions are depicted in Fig. 8.

The most striking feature is the observation of a significant cross section for the $3 n$ channel far below the Bass fu-

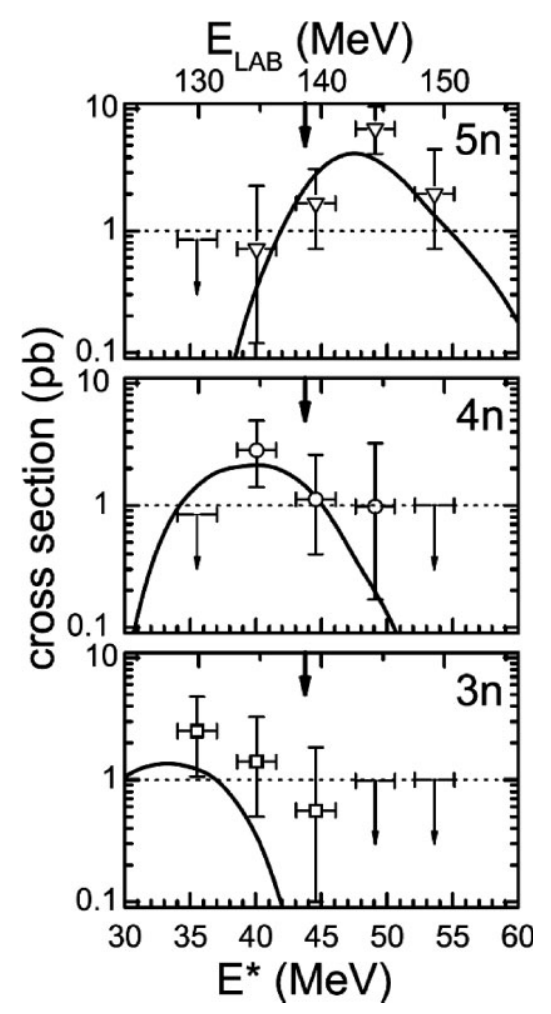

Fig. 8. Comparison of production cross sections measured for the reaction ${ }^{248} \mathrm{Cm}\left({ }^{26} \mathrm{Mg}, 3-5 n\right){ }^{269-271} \mathrm{Hs}$ in $[15,16]$ along with excitation functions calculated with the HIVAP code (lines) [43]. Cross-section limits are indicated by arrows. Error bars on cross section values correspond to $68 \%$ confidence intervals. Error bars on beam energies are $1.5 \mathrm{MeV}$ wide reflecting the energy spread inside the target material. The location of the Bass fusion barrier is indicated by the bold arrow. 
sion barrier similar in magnitude to the ones of the $4 n$ and $5 n$ channels at or above the Bass barrier. This result was rather unexpected and attributed to the situation where a projectile hits the polar side of the deformed target nucleus ${ }^{248} \mathrm{Cm}$. Thus, an elongated configuration with a lower Coulomb barrier is achieved, which allows the capture of a projectile with a high probability even at energies below the Bass barrier. Fusion enhancement due to such "orientation-effects" was observed in reactions of ${ }^{16} \mathrm{O}$ and ${ }^{30} \mathrm{Si}$ with ${ }^{238} \mathrm{U}$ targets $[52,53]$.

As can be seen in Fig. 8 the HIVAP calculations were rather accurate in predicting the maximum as well as the magnitude of the different evaporation channels. Generally, the cross sections are low and of the order of a few $\mathrm{pb}$ only and thus comparable with the ${ }^{48} \mathrm{Ca}$ induced reactions on actinide targets leading to superheavy elements. The efficient chemical separation method allowed investigating the reaction ${ }^{26} \mathrm{Mg}+{ }^{248} \mathrm{Cm}$ in some detail, despite the low production cross sections. In total 5 new nuclides were synthesized for the first time and a surprisingly high $3 n$ cross section was observed, holding some potential of this reaction mechanism to explore more neutron-rich, new nuclides.

\subsubsection{Excitation functions of the reaction ${ }^{36} \mathrm{~S}+{ }^{238} \mathrm{U}$}

According to the predictions by Liu et al. [42] the reaction ${ }^{36} \mathrm{~S}+{ }^{238} \mathrm{U}$ should produce the nuclide ${ }^{270} \mathrm{Hs}$ in the $4 n$ channel with twice the cross section compared to ${ }^{26} \mathrm{Mg}+{ }^{248} \mathrm{Cm}$ and therefore expectations were high.

As can be seen in Fig. 9 only one single event was observed at an excitation energy of $E^{*}=51 \mathrm{MeV}$, which could be attributed to the decay of a ${ }^{270} \mathrm{Hs}$ atom [47]. The production cross section of this single event was below $1 \mathrm{pb}$. For other reaction channels and at a lower excitation energy only upper cross section limits could be established. The cross section calculations by the HIVAP code (solid lines) seem to provide a more accurate picture than the predictions by Liu et al. [42], where the $Q$-value effect for this reaction was clearly overestimated. However, in order to get a more detailed picture, an additional measurement at $E^{*}=45 \mathrm{MeV}$ should be performed. Again the efficient chemical separation procedure allowed reaching a 1 -event cross section limit of $1 \mathrm{pb}$ within only 1 week of beam time.

\subsubsection{Excitation functions of the reaction ${ }^{48} \mathrm{Ca}+{ }^{226} \mathrm{Ra}$}

Only a preliminary analysis has been performed of the experiments on the reaction ${ }^{48} \mathrm{Ca}+{ }^{226} \mathrm{Ra}$ at the DGFRS [48]. At an excitation energy of $E^{*}=40 \mathrm{MeV}$, a preliminary production cross section of ${ }^{270} \mathrm{Hs}$ of $\approx 10 \mathrm{pb}$ was obtained. This value is in reasonable agreement with the results of the HIVAP code but again lower than predicted by Liu et al. [42]. Nevertheless, the influence of the favorable $Q$-value introduced by the ${ }^{48} \mathrm{Ca}$-projectile is impressive. Even though the reaction ${ }^{48} \mathrm{Ca}+{ }^{226} \mathrm{Ra}$ is the most symmetric of all the investigated reactions it appears that due to the favorable $Q$-value the highest production cross section for ${ }^{270} \mathrm{Hs}$ in the $4 n$ evaporation channel is realized. This result strongly supports the observation of high production cross sections in ${ }^{48} \mathrm{Ca}$ induced reactions with actinide targets to form superheavy elements with $Z=112$ to 118 .

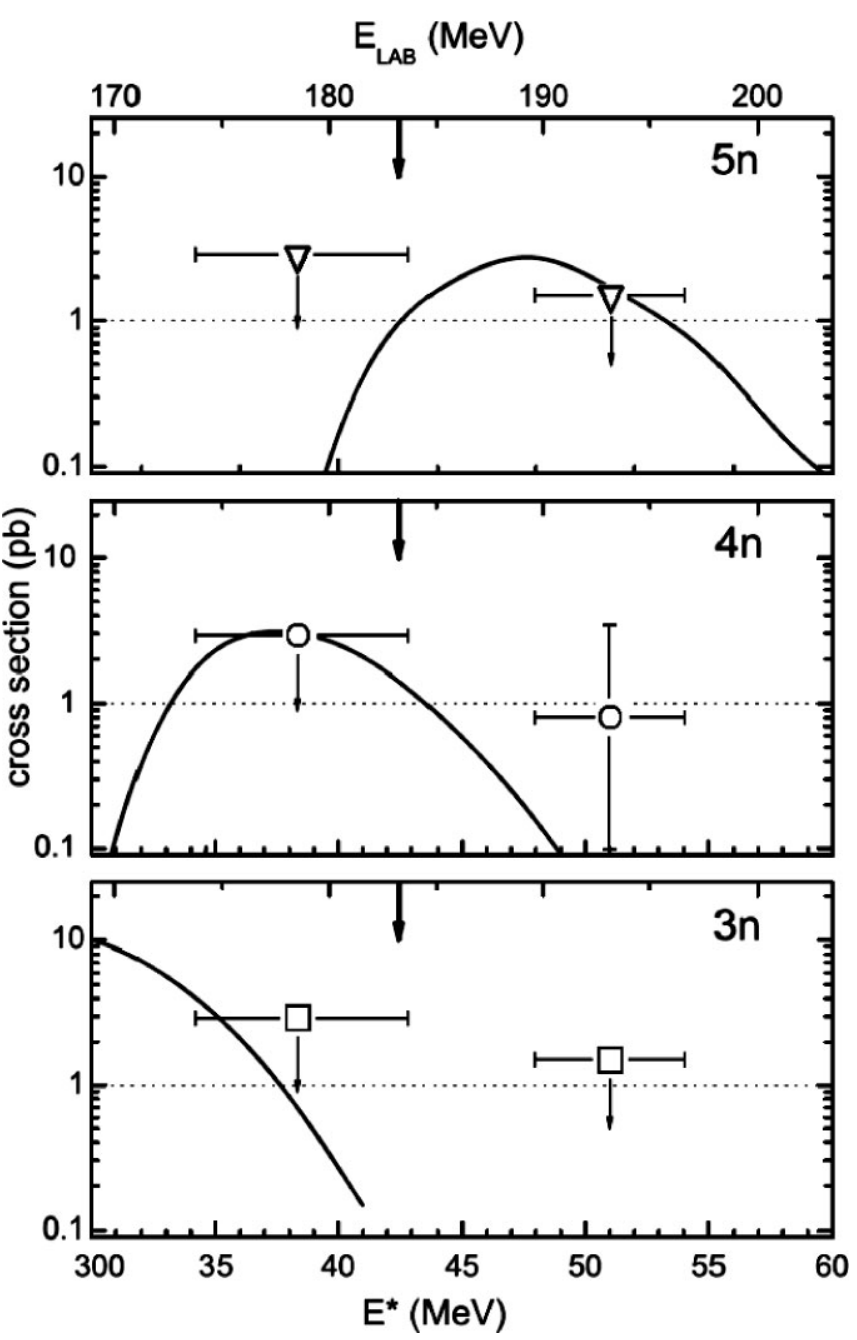

Fig. 9. Production cross sections and limits measured for the reaction ${ }^{238} \mathrm{U}\left({ }^{36} \mathrm{~S}, x n\right)^{274-x} \mathrm{Hs}$ [47] in comparison with HIVAP calculations (solid line) [43]. Arrows indicate the location of the Bass fusion barrier.

\section{References}

1. Münzenberg, G., Armbruster, P., Folger, H., Heßberger, F. P., Hofmann, S., Keller, J., Poppensieker, K., Reisdorf, W., Schmidt, K. H., Schött, H. J., Leino, M. E., Hingmann, R.: The identification of element 108. Z. Phys. A 317, 235-236 (1984).

2. Dragojeviæ, I., Gregorich, K. E., Düllmann, C. E., Dvorak, J., Ellison, P. A., Gates, J. M., Nelson, S. L., Stavsetra, L., Nitsche, H.: New isotope ${ }^{263}$ Hs. Phys. Rev. C 79, 011602(R) (2009).

3. Kaji, D., Morimoto, K., Sato, N., Ichikawa, T., Ideguchi, E., Ozeki, K., Haba, H., Koura, H., Kudou, Y., Ozawa, A., Sumita, T., Yamaguchi, T., Yoneda, A., Yoshida, A., Morita, K.: Production and decay properties of ${ }^{263}$ Hs. J. Phys. Soc. Japan 78, 035003 (2009).

4. Münzenberg, G., Armbruster, P., Berthes, G., Folger, H., Heßberger, F. P., Hofmann, S., Poppensieker, K., Reisdorf, W., Quint, B., Schmidt, K. H., Schött, H. J., Sümmerer, K., Zychor, I., Leino, M. E., Gollerthan, U., Hanelt, E.: Evidence for ${ }^{264} 108$, the heaviest known even-even isotope. Z. Phys. A 324, 489-490 (1986).

5. Münzenberg, G., Armbruster, P., Berthes, G., Folger, H., Heßberger, F. P., Hofmann, S., Keller, J., Poppensieker, K., Quint, A. B., Reisdorf, W., Schmidt, K. H., Schött, H. J., Sümmerer, K., Zychor, I., Leino, M. E., Hingmann, R., Gollerthan, U., Hanelt, E.: Observation of the isotopes ${ }^{264} 108$ and ${ }^{265} 108$. Z. Phys. A 328, 49-59 (1987).

6. Hofmann, S., Heßberger, F. P., Ackermann, D., Antalic, S., Cagarda, P., Cwiok, S., Kindler, B., Kojouharova, J., Lommel, B., Mann, R., Münzenberg, G., Popeko, A. G., Saro, S., Schött, H. J., 
Yeremin, A. V.: The new isotope ${ }^{270} 110$ and its decay products ${ }^{266} \mathrm{Hs}$ and ${ }^{262} \mathrm{Sg}$. Eur. Phys. J. A 10, 5-10 (2001).

7. Hofmann, S.: New elements - approaching $Z=114$. Rep. Prog. Phys. 61, 639-689 (1998).

8. Ginter, T. N., Gregorich, K. E., Loveland, W., Lee, D. M., Kirbach, U. W., Sudowe, R., Folden III, C. M., Patin, J. B., Seward, N., Wilk, P. A., Zielinski, P. M., Aleklett, K., Eichler, R., Nitsche, H., Hoffman, D. C.: Confirmation of production of element 110 by the ${ }^{208} \mathrm{~Pb}\left({ }^{64} \mathrm{Ni}, n\right)$ reaction. Phys. Rev. C 67, 064609 (2003).

9. Morita, K., Morimoto, K., Kaji, D., Haba, H., Ideguchi, E., Kanungo, R., Katori, K., Koura, H., Kudo, H., Ohnishi, T., Ozawa, A., Suda, T., Sueki, K., Tanihata, I., Xu, H., Yeremin, A. V., Yoneda, A., Yoshida, A., Zhao, Y. L., Zheng, T.: Production and decay of the isotope ${ }^{271} \mathrm{Ds}(Z=110)$. Eur. Phys. J. A 21, 257-263 (2004).

10. Nishio, K., Hofmann, S., Heßberger, F. P., Ackermann, D., Antalic, S., Aritomo, Y., Comas, V. F., Düllmann, C. E., Gorshkov, A., Graeger, R., Hagino, K., Heinz, S., Heredia, J. A., Hirose, K., Ikezoe, H., Khuyagbaatar, J., Kindler, B., Kojouharov, I., Lommel, B., Mann, R., Mitsuoka, S., Nagame, Y., Nishinaka, I., Ohtsuki, T., Popeko, A. G., Saro, S., Schädel, M., Türler, A., Watanabe, Y., Yakushev, A., Yeremin, A. V.: Nuclear orientation in the reaction ${ }^{34} \mathrm{~S}+{ }^{238} \mathrm{U}$ and synthesis of the new isotope ${ }^{268} \mathrm{Hs}$. Phys. Rev. C 82, 024611 (2010).

11. Hofmann, S., Ninov, V., Heßberger, F. P., Armbruster, P., Folger, H., Münzenberg, G., Schött, H. J., Popeko, A. G., Yeremin, A. V., Saro, S., Janik, R., Leino, M.: The new element 112. Z. Phys. A 354, 229-230 (1996).

12. Hofmann, S., Heßberger, F. P., Ackermann, D., Münzenberg, G., Antalic, S., Cagarda, P., Kindler, B., Kojouharova, J., Leino, M., Lommel, B., Mann, R., Popeko, A. G., Reshitko, S., Saro, S., Uusitalo, J., Yeremin, A. V.: New results on elements 111 and 112. Eur. Phys. J. A 14, 147-157 (2002).

13. Morita, K., Morimoto, K., Kaji, D., Akiyama, K., Goto, S., Haba, H., Ideguchi, E., Katori, K., Koura, H., Kudo, H., Ohnishi, T., Ozawa, A., Suda, T., Sueki, K., Tokanai, F., Yamaguchi, H., Yoneda, A., Yoshida, A.: Experiment on synthesis of an isotope ${ }^{277} 112$ by ${ }^{208} \mathrm{~Pb}+{ }^{70} \mathrm{Zn}$ reaction. J. Phys. Soc. Japan 76, 043201 (2007).

14. Düllmann, C. E., Brüchle, W., Dressler, R., Eberhardt, K., Eichler, B., Eichler, R., Gäggeler, H. W., Ginter, T. N., Glaus, F., Gregorich, K. E., Hoffman, D. C., Jäger, E., Jost, D. T., Kirbach, U. W., Lee, D. M., Nitsche, H., Patin, J. B., Pershina, V., Piguet, D., Qin, Z.， Schädel, M., Schausten, B., Schimpf, E., Schött, H. J., Soverna, S., Sudowe, R., Thörle, P., Timokhin, S. N., Trautmann, N., Türler, A., Vahle, A., Wirth, G., Yakushev, A. B., Zielinski, P. M.: Chemical investigation of hassium (element 108). Nature 418, 859-862 (2002).

15. Dvorak, J., Brüchle, W., Chelnokov, M., Dressler, R., Düllmann, C. E., Eberhardt, K., Gorshkov, V., Jäger, E., Krücken, R., Kuznetsov, A., Nagame, Y., Nebel, F., Novackova, Z., Qin, Z., Schädel, M., Schausten, B., Schimpf, E., Semchenkov, A., Thörle, P., Türler, A., Wegrzecki, M., Wierczinski, B., Yakushev, A., Yeremin, A.: Doubly magic nucleus ${ }^{270} \mathrm{Hs}_{162}$. Phys. Rev. Lett. 97, 242501 (2006).

16. Dvorak, J., Brüchle, W., Chelnokov, M., Dressler, R., Düllmann, C. E., Dvorakova, Z., Eberhardt, K., Jäger, E., Krücken, R., Kuznetsov, A., Nagame, Y., Nebel, F., Nishio, K., Perego, R., Qin, Z., Schädel, M., Schausten, B., Schimpf, E., Schuber, R., Semchenkov, A., Thörle, P., Türler, A., Wegrzecki, M., Wierczinski, B., Yakushev, A., Yeremin, A.: Observation of the $3 n$ evaporation channel in the complete hot-fusion reaction ${ }^{26} \mathrm{Mg}+{ }^{248} \mathrm{Cm}$ leading to the new superheavy nuclide ${ }^{271} \mathrm{Hs}$. Phys. Rev. Lett. 100, 132503 (2008).

17. Ellison, P. A., Gregorich, K. E., Berryman, J. S., Bleuel, D. L., Clark, R. M., Dragojeviæ, I., Dvorak, J., Fallon, P., FinemanSotomayor, C., Gates, J. M., Gothe, O. R., Lee, I. Y., Loveland, W. D., McLaughlin, J. P., Paschalis, S., Petri, M., Qian, J., Stavsetra, L., Wiedeking, M., Nitsche, H.: New superheavy element isotopes: ${ }^{242} \mathrm{Pu}\left({ }^{48} \mathrm{Ca}, 5 n\right){ }^{285} 114$. Phys. Rev. Lett. 105, 182701 (2010).

18. Oganessian, Y.: Heaviest nuclei from ${ }^{48} \mathrm{Ca}$-induced reactions. J. Phys. G 34, R165-R242 (2007).
19. Düllmann, C. E., Schädel, M., Yakushev, A., Türler, A., Eberhardt, K., Kratz, J. V., Ackermann, D., Andersson, L.-L., Block, M., Brüchle, W., Dvorak, J., Essel, H. G., Ellison, P. A., Even, J., Gates, J. M., Gorshkov, A., Graeger, R., Gregorich, K. E., Hartmann, W., Herzberg, R.-D., Heßberger, F. P., Hild, D., Hübner, A., Jäger, E., Khuyagbaatar, J., Kindler, B., Krier, J., Kurz, N., Lahiri, S., Liebe, D., Lommel, B., Maiti, M., Nitsche, H., Omtvedt, J. P., Parr, E., Rudolph, D., Runke, J., Schausten, B., Schimpf, E., Semchenkov, A., Steiner, J., Thörle-Pospiech, P., Uusitalo, J., Wegrzecki, M., Wiehl, N.: Production and decay of element 114: High cross sections and the new nucleus ${ }^{277} \mathrm{Hs}$. Phys. Rev. Lett. 104, 252701 (2010).

20. Patyk, Z., Skalski, J., Sobiczewski, A., Cwiok, S.: Potentialenergy and spontaneous-fission half-lives for heavy and superheavy nuclei. Nucl. Phys. A 502, C591-C599 (1989).

21. Patyk, Z., Sobiczewski, A.: Ground-state properties of the heaviest nuclei analyzed in a multidimensional deformation space. Nucl. Phys. A 533, 132-152 (1991).

22. Bender, M., Heenen, P. H., Reinhard, P. G.: Self-consistent meanfield models for nuclear structure. Rev. Mod. Phys. 75, 121-180 (2003).

23. Smolañczuk, R., Skalski, J., Sobiczewski, A.: Spontaneous-fission half-lives of deformed superheavy nuclei. Phys. Rev. C 52, 1871-1880 (1995).

24. Dvorak, J., Brüchle, W., Düllmann, C. E., Dvorakova, Z., Eberhardt, K., Eichler, R., Jäger, E., Nagame, Y., Qin, Z., Schädel, M., Schausten, B., Schimpf, E., Schuber, R., Semchenkov, A., Thörle, P., Türler, A., Wegrzecki, M., Yakushev, A.: Cross section limits for the ${ }^{248} \mathrm{Cm}\left({ }^{25} \mathrm{Mg}, 4 n-5 n\right){ }^{268,269} \mathrm{Hs}$ reactions. Phys. Rev. C 79, 037602 (2009).

25. Oganessian, Y. T., Dmitriev, S. N., Yeremin, A. V., Aksenov, N. V., Bozhikov, G. A., Chepigin, V. I., Chelnokov, M. L., Lebedev, V. Y., Malyshev, O. N., Petrushkin, O. V., Shishkin, S. V., Svirikhin, A. I., Tereshatov, E. E., Vostokin, G. K.: Attempt to produce the isotopes of element 108 in the fusion reaction ${ }^{136} \mathrm{Xe}+{ }^{136} \mathrm{Xe}$. Phys. Rev. C 79, 024608 (2009).

26. Düllmann, C. E. and Türler, A.: ${ }^{248} \mathrm{Cm}\left({ }^{22} \mathrm{Ne}, x n\right)^{270-x} \mathrm{Sg}$ reaction and the decay properties of ${ }^{265} \mathrm{Sg}$ reexamined. Phys. Rev. C 77, 064320 (2008).

27. Sobiczewski, A., Muntian, I., Patyk, Z.: Problem of "deformed" superheavy nuclei. Phys. Rev. C 63, 034306 (2001).

28. Möller, P., Nix, J. R., Kratz, K. L.: Nuclear properties for astrophysical and radioactive-ion-beam applications. Atom. Data Nucl. Data Tables 66, 131-343 (1997).

29. Liran, S., Marinov, A., Zeldes, N.: Applications of semiempirical shell model masses based on a proton magic number $Z=126$ to heavy and superheavy nuclei. Phys. Rev. C 66, 024303 (2002).

30. Ren, Z.: Binding energies of even-event superheavy nuclei. Phys. At. Nucl. 66, 1557-1560 (2003).

31. Kowal, M., Jachimowicz, P., Sobiczewski, A.: Fission barriers for even-even superheavy nuclei. Phys. Rev. C 82, 014303 (2010).

32. Lazarev, Y. A., Lobanov, Y. V., Oganessian, Y. T., Utyonkov, V. K., Abdullin, F. S., Buklanov, G. V., Gikal, B. N., Iliev, S., Mezentsev, A. N., Polyakov, A. N., Sedykh, I. M., Shirokovsky, I. V., Subbotin, V. G., Sukhov, A. M., Tsyganov, Y. S., Zhuchko, V. E., Lougheed, R. W., Moody, K. J., Wild, J. F., Hulet, E. K., Mcquaid, J.H.: Discovery of enhanced nuclear stability near the deformed shells $N=162$ and $Z=108$. Phys. Rev. Lett. 73, 624 (1994).

33. Ghiorso, A., Nurmia, M., Eskola, K., Eskola, P.: ${ }^{261}$ Rf, new isotope of element 104. Phys. Lett. B 32, 95-98 (1970).

34. Somerville, L. P., Nurmia, M. J., Nitschke, J. M., Ghiorso, A., Hulet, E. K., Lougheed, R. W.: Spontaneous fission of rutherfordium isotopes. Phys. Rev. C 31, 1801-1815 (1985).

35. Lane, M. R., Gregorich, K. E., Lee, D. M., Mohar, M. F., Hsu, M., Kacher, C. D., Kadkhodayan, B., Neu, M. P., Stoyer, N. J., Sylwester, E. R., Yang, J. C., Hoffman, D. C.: Spontaneous fission properties of ${ }^{262}$ Rf. Phys. Rev. C 53, 2893 (1996).

36. Schädel, M., Brüchle, W., Dressler, R., Eichler, B., Gäggeler, H. W., Günther, R., Gregorich, K. E., Hoffman, D. C., Hübener, S., Jost, D. T., Kratz, J. V., Paulus, W., Schumann, D., Timokhin, S., Trautmann, N., Türler, A.: Chemical properties of element 106 (seaborgium). Nature 388, 55-57 (1997). 
37. Türler, A., Dressler, R., Eichler, B., Gäggeler, H. W., Jost, D. T., Schädel, M., Brüchle, W., Gregorich, K. E., Trautmann, N., Taut, S.: Decay properties of ${ }^{265} \mathrm{Sg}(Z=106)$ and ${ }^{266} \mathrm{Sg}(Z=106)$. Phys. Rev. C 57, 1648 (1998).

38. Türler, A., Brüchle, W., Dressler, R., Eichler, B., Eichler, R., Gäggeler, H. W., Gärtner, M., Glatz, J.-P., Gregorich, K. E., Hübener, S., Jost, D. T., Lebedev, V. Y., Pershina, V. G., Schädel, M., Taut, S., Timokhin, S. N., Trautmann, N., Vahle, A., Yakushev, A. B.: First measurement of a thermochemical property of a seaborgium compound. Angew. Chem. Intl. Ed. 38, 2212 (1999).

39. Schädel, M., Brüchle, W., Jäger, E., Schausten, B., Wirth, G., Paulus, W., Günther, R., Eberhardt, K., Kratz, J. V., Seibert, A., Strub, E., Thörle, P., Trautmann, N., Waldek, A., Zauner, S., Schumann, D., Kirbach, U., Kubica, B., Misiak, R., Nagame, Y., Gregorich, K. E.: Aqueous chemistry of seaborgium $(Z=106)$. Radiochim. Acta 83, 163-165 (1998).

40. Hübener, S., Taut, S., Vahle, A., Dressler, R., Eichler, B., Gäggeler, H. W., Jost, D. T., Piguet, D., Türler, A., Brüchle, W., Jäger, E., Schädel, M., Schimpf, E., Kirbach, U., Trautmann, N., Yakushev, A. B.: Physico-chemical characterization of seaborgium as oxide hydroxide. Radiochim. Acta 89, 737-741 (2001).

41. Muntian, I., Hofmann, S., Patyk, Z., Sobiczewski, A.: Properties of heaviest nuclei. Acta Phys. Pol. B 34, 2073-2082 (2003).

42. Liu, Z. H., Bao, J. D.: $Q$-value effects on the production of superheavy nuclei. Phys. Rev. C 74, 057602 (2006).

43. Reisdorf, W., Schädel, M.: How well do we understand the synthesis of heavy elements by heavy-ion induced fusion? Z. Phys. A 343, 47-57 (1992).

44. Zagrebaev, V., Greiner, W.: Synthesis of superheavy nuclei: a search for new production reactions. Phys. Rev. C 78, 034610 (2008).

45. Eberhardt, K., Brüchle, W., Düllmann, C. E., Gregorich, K. E., Hartmann, W., Hübner, A., Jäger, E., Kindler, B., Kratz, J. V., Liebe, D., Lommel, B., Maier, H.-J., Schädel, M., Schausten, B., Schimpf, E., Semchenkov, A., Steiner, J., Szerypo, J., Thörle, P., Türler, A., Yakushev, A.: Preparation of targets for the gas-filled recoil separator TASCA by electrochemical deposition and design of the TASCA target wheel assembly. Nucl. Instrum. Methods A 590, 134-140 (2008).
46. Schädel, M.: The Chemistry of Superheavy Elements. Kluwer Academic Publishers, Dordrecht, The Netherlands (2003).

47. Graeger, R., Ackermann, D., Chelnokov, M., Chepigin, V., Düllmann, C. E., Dvorak, J., Even, J., Gorshkov, A., Heßberger, F. P., Hild, D., Hübner, A., Jäger, E., Khuyagbaatar, J., Kindler, B., Kratz, J. V., Krier, J., Kuznetsov, A., Lommel, B., Nishio, K., Nitsche, H., Omtvedt, J. P., Petrushkin, O., Rudolph, D., Runke, J., Samadani, F., Schädel, M., Schausten, B.: Experimental study of the ${ }^{238} \mathrm{U}\left({ }^{36} \mathrm{~S}, 3-5 n\right)^{269-271} \mathrm{Hs}$ reaction leading to the observation of ${ }^{270}$ Hs. Phys. Rev. C 81, 061601 (2010).

48. Graeger, R.: In: $Q$-value effects in the synthesis of superheavy elements. PhD thesis, Technische Universität München, Garching (2010).

49. Haba, H., Kaji, D., Kikunaga, H., Kudou, Y., Morimoto, K., Morita, K., Ozeki, K., Sumita, T., Yoneda, A., Kasamatsu, Y., Komori, Y., Ooe, K., Shinohara, A., Production and decay properties of the 1.9-s isomeric state in ${ }^{261}$ Rf. Phys. Rev. C 83, 034602 (2011).

50. Gorshkov, A.: In: A new focal plane detector for the gas-filled separator TASCA. PhD thesis, Technische Universität München, Garching (2010).

51. Kratz, J. V., Nähler, A., Rieth, U., Kronenberg, A., Kuczewski, B., Strub, E., Brüchle, W., Schädel, M., Schausten, B., Türler, A., Gäggeler, H. W., Jost, D. T., Gregorich, K. E., Nitsche, H., Laue, C., Sudowe, R., Wilk, P. A.: An EC-branch in the decay of 27-s ${ }^{263} \mathrm{Db}$ : Evidence for the isotope ${ }^{263} \mathrm{Rf}$. Radiochim. Acta 91, 59-62 (2003).

52. Nishio, K., Ikezoe, H., Nagame, Y., Asai, M., Tsukada, K., Mitsuoka, S., Tsuruta, K., Satou, K., Lin, C. J., Ohsawa, T.: Evidence of complete fusion in the sub-barrier ${ }^{16} \mathrm{O}+{ }^{238} \mathrm{U}$ reaction. Phys. Rev. Lett. 93, 162701 (2004).

53. Nishio, K., Hofmann, S., Heßberger, F. P., Ackermann, D., Antalic, S., Comas, V. F., Gan, Z., Heinz, S., Heredia, J. A., Ikezoe, H., Khuyagbaatar, J., Kindler, B., Kojouharov, I., Kuusiniemi, P., Lommel, B., Mann, R., Mazzocco, M., Mitsuoka, S., Nagame, Y., Ohtsuki, T., Popeko, A. G., Saro, S., Schött, H. J., Sulignano, B., Svirikhin, A. I., Tsukada, K., Tsuruta, K., Yeremin, A. V.: Measurement of evaporation residue cross-sections of the reaction ${ }^{30} \mathrm{Si}+{ }^{238} \mathrm{U}$ at subbarrier energies. Eur. Phys. J. A 29, 281-287 (2006). 